\title{
Repercusión de la infección por SARS-COV-2 en las intervenciones de Girugía Plástica en Andalucía [Espaîa] durante la primera fase de pandemia COVID-19
}

\section{Impact of SARS-CoV-2 infection in Plastic Surgery procedures during first period of COVID-19 pandemic in Andalusian surgery units [Spain]}

Alberto REDONDO CAMACHO*, Marta REDONDO LAVIRGEN** Carmen TORRE BELTRAMI***

\section{Resumen}

Introducción y objetivo. Dentro del contexto de la pandemia COVID-19 del 2020 en nuestro país, el objetivo principal de este estudio es determinar la incidencia de contagios por SARS-CoV-2 en pacientes intervenidos por Cirugía Plástica en las Unidades o Servicios de Andalucía (España) en los tiempos pre y posoperatorios, mostrar si ha existido un incremento en la incidencia de complicaciones posquirúrgicas durante la pandemia, y si se han observado complicaciones relacionadas con el virus distintas a las ocurridas en períodos previos.

Analizamos también la influencia del tipo de anestesia, tiempo quirúrgico o tipo de cirugía en los resultados y en la posibilidad de contagio.

Material y método. Análisis observacional del comportamiento y evolución de los pacientes intervenidos en las Unidades de Cirugía Plástica de los hospitales de Sevilla, Málaga, Córdoba, Granada y Cádiz, entre el 9 de marzo y el 30 de abril de 2020. Recogimos datos relacionados con la infección por SARS-CoV-2 de 703 pacientes, incluyendo resultados de PCR y serología pre y posoperatorias y datos relacionados con el procedimiento quirúrgico, cuando fue posible. Todo el registro se realizó en una base de datos anonimizada común y analizados mediante el software estadístico SPSS ${ }^{\circledR}$.

Resultados. Todos los casos tuvieron un desenlace favorable, más del $96 \%$ de los pacientes no experimentaron ningún tipo de complicaciones y cuando aparecieron, se resolvieron con éxito. No se diagnosticaron entre ellos casos de SARS-CoV-2 y la duración de las intervenciones no se relacionó con mayor incidencia de contagio. Además, ninguno de los tipos de anestesia n de las cirugías se relacionó con mayor incidencia de infección por este virus.

Conclusiones. Pese a las circunstancias sanitarias en las que se realizaron las cirugías y la ausencia de protocolos en las fases iniciales, no observamos contagios en los pacientes tratados ni complicaciones vinculadas a la presencia del virus; tampoco fueron factores significativos el tipo de anestesia ni la duración de la cirugía. Estos resultados apoyan que, cumpliendo los protocolos de cribado para COVID-19, pruebas PCR y medidas preventivas de centro, fue seguro realizar estas cirugías.

\section{Palabras clave COVID-19, Pandemia, Complicaciones Cirugía Plástica.}

Nivel de evidencia científica
Recibido [esta versión]
Aceptado

4c Terapéutico 30 diciembre / 2020 18 mayo / 2021

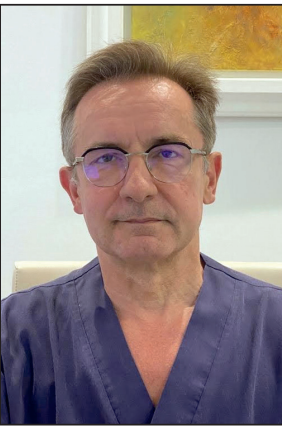

Redondo Camacho A.

Conflicto de intereses: Los autores declaran no tener ningún interés financiero relacionado con el contenido de este artículo. Financiación: No hubo fuentes externas de financiación para este trabajo.

Background and objective. Within the context of the 2020 COVID-19 pandemic in our country, the main objective of this study is to determine the incidence of SARS-CoV-2 infections in patients operated on for Plastic Surgery in Units or Services in Andalusia (Spain) in the pre and postoperative times, show if there has been an increase in the incidence of postoperative complications during the pandemic, and if complications related to the virus other than those that occurred in previous periods have been observed. We also analyze the influence of the type of anesthesia, surgical time or type of surgery on the results and the possibility of contagion.

Methods. Observational analysis of the behavior and evolution of patients operated on in the Plastic Surgery Units of the hospitals of Seville, Malaga, Córdoba, Granada and Cádiz, between March 9 and April 30, 2020 We collected data related to infection by SARS-CoV-2 of 703 patients, including pre and postoperative PCR and serology results and data related to the surgical procedure, when possible. All registration was carried out in a common anonymized database and analyzed using the SPSS ${ }^{\circledR}$ statistical software.

Results. All the cases had a favorable outcome, more than $96 \%$ of the patients did not experience any type of complications and when they appeared, they were resolved successfully. No cases of SARS-CoV-2 were diagnosed among them and the duration of the surgeries was not related to a higher incidence of contagion. In addition, none of the types of anesthesia or surgeries were associated with a higher incidence of infection by this virus.

Conclusions. Despite the health circumstances in which the surgeries were performed and the absence of protocols in the initial phases, we did not observe infections in the treated patients or complications related to the presence of the virus; the type of anesthesia and the duration of surgery were not significant factors either. These results support that, by complying with the screening protocols for COVID-19, PCR tests and preventive measures of the center, it was safe to perform these surgeries.

\begin{tabular}{lr}
$\begin{array}{l}\text { Key words } \\
\text { COVID 19, Pandemic, Complications, } \\
\text { Plastic Surgery. }\end{array}$ \\
$\begin{array}{l}\text { Level of evidence } \\
\text { Received [this version] } \\
\text { Accepted }\end{array}$ & $\begin{array}{r}\text { Decem Therapeutic } \\
\text { Der / } 2020\end{array}$ \\
\hline
\end{tabular}


Introducción

El día 31 de Diciembre de 2019, la Comisión Nacional de Salud y Sanidad de Wuhan (provincia de Hubei, China) ${ }^{(1-4)}$ informó de la detección en un grupo de 27 ciudadanos de una infección neumónica de etiología desconocida. De estos, 7 se encontraban en estado grave. ${ }^{(5)} \mathrm{El}$ 7 de enero de 2020 las autoridades chinas identificaron como agente causante del brote un nuevo tipo de virus de la familia Coronaviridae que se denominó SARS-CoV-2 y la patología derivada de dicha infección fue denominada COVID-19 (acrónimo del inglés coronavirus disease, al que se añade el 19 por el año en el que se conoció el primer caso). Las autoridades chinas compartieron la secuencia genética del virus el 12 de enero del 2020, así como sus características moleculares y patogénicas. ${ }^{(5-9)}$

Los estudios en los pacientes afectados de COVID-19 describen una clínica consistente en: fiebre (47\%), tos seca o productiva $(25 \%)$, dolor de garganta $(16 \%)$, astenia $(6 \%)$ y dolor $(5 \%) .{ }^{(8)}$ En España, con 18.609 casos notificados en la fecha en que se realizó este estudio, los síntomas más frecuentes fueron: fiebre o reciente historia de fiebre $(68.7 \%)$, tos $(68.1 \%)$, dolor de garganta (24.1\%), disnea (31\%), escalofríos (27\%), vómitos (6\%) y diarrea $(14 \%){ }^{(9)}$ El $85.6 \%$ y $88 \%$ de los pacientes reportaron pérdida olfativa y ageusia respectivamente. Se detectó asociación significativa entre ambos trastornos $(\mathrm{p}<0.001)$. La anosmia apareció antes que el resto de síntomas en el $11.8 \%$ de los casos. ${ }^{(10)}$

El 11 de marzo de 2020, la Organización Mundial de la Salud (OMS) declaró la COVID-19 como pandemia mundial; se registraban ya 125.865 casos diagnosticados en todo el mundo. España, en esa época, detectaba 1/10 casos con un total de 3.274 casos. El primer estudio de seroprevalencia realizado posteriormente determinó que un $5.2 \%$ de la población tuvo contacto con el virus, es decir, 2.5 millones de personas.

El impacto de la pandemia generó una situación de incertidumbre respecto a las medidas a tomar ante cirugías programadas no urgentes, ${ }^{(11)}$ pues algunas publicaciones planteaban un severo incremento del riesgo operatorio relacionado con la COVID-19 que se asociaba a factores como: tiempos quirúrgicos, tipos de anestesia, área corporal intervenida y otros. No existían en aquel momento protocolos claros en cuanto a la selección de los pacientes en función de situación clínica o pruebas complementarias necesarias. Por ello, las sociedades científicas de cirugía propusieron un cese preventivo de las intervenciones quirúrgicas no urgentes que llevó a una importante reducción de los procesos llevados a cabo en todas las especialidades y lógicamente, también en la nuestra.
En España, ante las circunstancias sobrevenidas, asociaciones de cirugía de distintas disciplinas como la AEC (Asociación Española de Cirujanos), ${ }^{(12,13)}$ la SEOQ (Sociedad Española de Cirugía Oncológica) o la propia SECPRE (Sociedad Española de Cirugía Plástica, Reparadora y Estética), elaboraron sus recomendaciones respecto a los procedimientos a realizar durante el período de pandemia de la COVID-19. Así la SECPRE(14) propuso:

- Reducir, posponer o cancelar las consultas y operaciones de Cirugía Plástica que no fueran de urgencia vital con el fin de no sobrecargar las estructuras hospitalarias ante la situación asistencial provocada por la pandemia.

- En el caso de pacientes que se hubieran sometido recientemente a intervenciones quirúrgicas y aunque se ha asegurado que no corren más riesgo que otras personas a la hora de contraer el virus por este motivo, la comunicación debe ser continua para controlar su evolución.

- Reducir las consultas presenciales mediante la potenciación de las consultas no presenciales o con agendas mixtas, siempre que fuera posible.

- En caso de requerir una consulta presencial, habilitar un sistema de despistaje previo de infección activa por SARS-CoV-2 e implementar medidas para el distanciamiento físico, higiene, uso de mascarillas y otros elementos de barrera para pacientes y profesionales.

Evitar las exploraciones y curas que supongan un riesgo de generación de aerosoles y salpicaduras o realizarlas utilizando el equipo de protección individual correspondiente.

- Ingreso hospitalario de los pacientes en el mismo día de la cirugía y evaluación del soporte sociofamiliar y de asistencia domiciliaria disponible para una posible alta precoz.

- Formación y restricción del número de visitantes y acompañantes al máximo durante la estancia hospitalaria.

El objetivo de este estudio es determinar el impacto y repercusiones que ha tenido la infección por SARS-CoV-2 en las intervenciones de Cirugía Plástica en nuestra región, Andalucía, comunidad autónoma situada al sur de España, compuesta por las provincias de Sevilla, Almería, Cádiz, Córdoba, Granada, Huelva, Málaga y Jaén, analizando el número de contagios ocurridos que se pudiesen relacionar con los procedimientos, así como estudiar si han existido complicaciones derivadas de la COVID-19 con el fin de objetivar la seguridad de los procedimientos quirúrgicos siguiendo las recomendaciones. 


\section{Material y método}

Realizamos un estudio retrospectivo, descriptivo, observacional de carácter transversal, que analiza una serie de 703 casos de pacientes intervenidos quirúrgicamente en las unidades de Cirugía Plástica de Cádiz, Sevilla, Córdoba, Málaga y Granada en Andalucía (España) en el período comprendido entre el 9 de marzo de 2020 y el 30 de abril de 2020. Incluimos todos los pacientes que fueron atendidos en ellas, dentro del sistema de salud público español

Tras realizar la correspondiente entrevista con los pacientes que cumplían los criterios de inclusión, recogimos los siguientes datos para las variables y medidas del estudio:

- Características del paciente: edad (años), sexo, índice de masa corporal IMC $\left(\mathrm{Kg} / \mathrm{m}^{2}\right)$, riesgo anestésico según niveles ASA I, II, III, IV, V.

- Comorbilidades: hipertensión (presente o ausente), enfermedad pulmonar obstructiva crónica (EPOC), asma (presente o ausente), diabetes mellitus (presente o ausente) o cardiopatía (presente o ausente).

- Características clínicas: presencia de síntomas de COVID-19 preoperatorios (positivos, negativos, no valorado); presencia de síntomas de COVID-19 posoperatorios (positivos, negativos, no valorado); categorías de infección COVID-19: caso confirmado, caso probable (criterio clínico y radiológico compatible con COVID-19 pero no confirmado por prueba), caso descartado (prueba PCR o test diagnóstico negativo de antígenos o anticuerpos que descarta infección).

- Pruebas complementarias: estudio radiológico de tórax preoperatorio (normal, anormal); PCR SARSCoV-2 cualitativa preoperatoria (positiva, negativa, no efectuada, indeterminada; serología COVID-19 preoperatoria (positiva, negativa, no efectuada); en caso positivo, título de IgM y de IgG (en unidad dilucional); en caso de clínica compatible con COVID-19 posquirúrgica: día de inicio desde la intervención; PCR cualitativa poscirugía (positiva, negativa, no efectuada, indeterminada); ingreso en Unidad de Cuidados Intensivos (UCI) y desenlace (alta, fallecimiento).

- Cirugía: tipo de anestesia (general, regional, local); tipo de cirugía (urgente, programada); nombre del procedimiento quirúrgico y código numérico CIE-10 (acrónimo de la Clasificación Internacional de Enfermedades, $10^{\mathrm{a}}$ edición, correspondiente a la versión en español de la versión en inglés ICD, siglas de International Statistical Classification of Diseases and Related Health Problems); duración de la cirugía en minutos; días de ingreso (número de días) (menor ambulatorio, mayor ambulatorio); complicaciones quirúrgicas sistémicas (ninguna, respiratoria cardiovascular, ambas, otras); complicaciones quirúrgicas locales (sangrado, dehiscencia, necrosis, infección); en caso de clínica compatible con COVID-19 posquirúrgica: día de inicio desde la intervención; PCR cualitativa poscirugía (positiva, negativa, no efectuada, indeterminada); ingreso en UCI y desenlace (alta, fallecimiento).

Tomamos los datos que constaban en la historia clínica de 703 pacientes previamente valorados en consulta de los distintos centros hospitalarios y los recogimos con el sistema de información Diraya, sistema que se utiliza en el Servicio Andaluz de Salud como soporte de la historia clínica electrónica y que integra toda la información de salud de cada una de las personas atendidas en los centros sanitarios para que esté disponible en el lugar y momento en que sea necesario para atenderle y sirve también para la gestión del propio sistema sanitario. Consultamos específicamente sobre síntomas relacionados con la COVID-19 que hubiesen podido padecer en días anteriores. Clasificamos los procedimientos quirúrgicos utilizando los códigos correspondientes al CIE-10 (descrito previamente).

En todos los centros se empleó el mismo modelo de recogida de variables para la base de datos, y se consensuaron las mismas determinaciones y test para la detección del virus SARS-CoV-2. Fue posible obtener la base de datos final cuando habían transcurrido un máximo de 5 meses (marzo/2020-agosto/2020) desde el inicio de la recogida de datos para el estudio. Esta base fue analizada con el software IBM SPSS ${ }^{\circledR}$ Statistics, con la que obtuvimos las frecuencias, incidencias y porcentajes referentes a los datos además de realizar los cruces precisos de las variables para obtener los datos estadísticos.

Para obtener los datos referentes a los resultados que más se han cuestionado (riesgo de infección relacionada con tipo de anestesia, tiempo quirúrgico o región corporal) se procedió al análisis estadístico de las variables establecidas: el tipo de anestesia relacionado con las complicaciones ocurridas y la incidencia de infección posoperatoria, así como los tipos de intervenciones más realizadas.

\section{Resultados}

Recogimos los datos de un total de 703 pacientes con edades comprendidas entre los 8 y los 96 años (media de 57 años). De los pacientes intervenidos, 399 fueron mujeres y 304 hombres. 
El procedimiento más realizado fue la exéresis de lesiones cutáneas (CIE-10: 0HC1XZZ), con 177 intervenciones realizadas en total entre las que predominó la exéresis de neoplasias en cabeza y cuello. La segunda intervención más realizada fue la cirugía de reconstrucción mamaria inmediata, con un total de 52 intervenciones, con todas sus variantes y a continuación la exéresis y linfadenectomía de ganglio centinela de melanoma con 30 intervenciones. Destacar que durante este mismo período se realizaron 4 microcirugías correspondientes a colgajos libres.

La sospecha clínica de infección por síntomas compatibles apareció en el 4\% de los pacientes, obteniéndose los resultados de PCR negativa en todos los casos. Se realizaron un total de 275 pruebas de PCR preoperatorias con resultado negativo y en 428 casos la prueba no se realizó. La serología preoperatoria fue considerablemente menos realizada: 6 serologías en total, con solo 1 positivo para $\mathrm{IgG}$.

No se diagnosticó ningún caso de COVID-19 activa preoperatoria y se diagnosticó una infección pasada. Tampoco fueron diagnosticados casos de COVID-19 en el posoperatorio.

Algunas publicaciones plantean la posible relación entre el tipo de anestesia utilizada y la aparición de complicaciones sistémicas, ${ }^{(15)}$ locales o vinculadas a la infección por SARS-CoV-2. En nuestro estudio no encontramos una relación significativa entre el tipo de anestesia y las complicaciones ocurridas, con 48 anestesias regionales, 393 locales, 259 generales y 3 pérdidas de datos sobre la información del tipo de anestesia (Gráfico 1). Hubo 3 complicaciones sistémicas en pacientes intervenidos con anestesia general, 2 de ellas correspondientes a complicaciones respiratorias debidas a reagudizaciones de patología respiratoria crónica: una tras cirugía de injerto cutáneo en quemaduras de extremidad superior y la otra en una paciente intervenida de reconstrucción mamaria, así como 1 caso de complicación cardiovas-

Gráfico 1. Relación entre el tipo de anestesia utilizada y las complicaciones ocurridas.

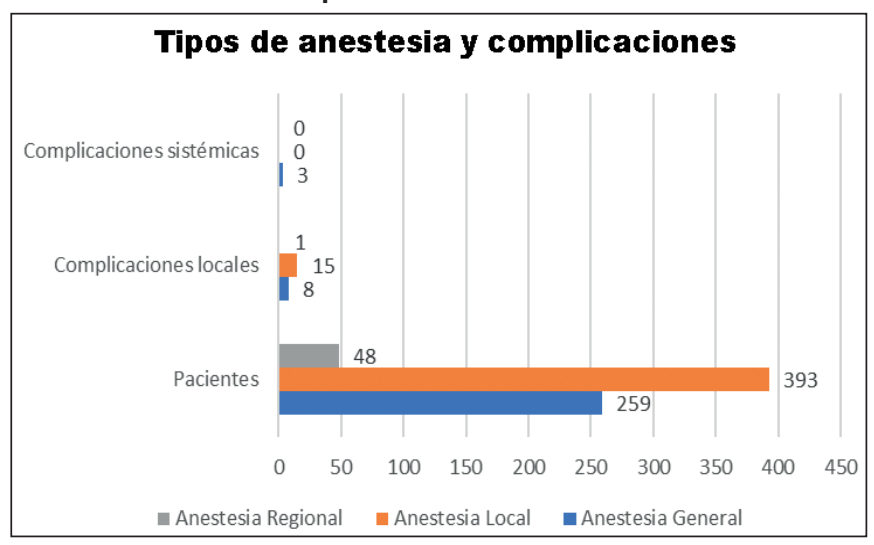

*Nota: el total de pacientes suma 700 porque hubo 3 pérdidas de datos sobre la información del tipo de anestesia cular en paciente con patología conocida cardiovascular previa intervenido de exéresis de tumor cutáneo. Fueron 24 las complicaciones locales: 1 en anestesia regional, 15 en anestesia local y 8 en anestesia general; las más frecuentes fueron los sangrados y las dehiscencias de sutura. Observamos un mayor número de complicaciones locales en intervenciones que se realizaron con anestesia local, pero las cifras se igualan con las de los períodos de normalidad. ${ }^{(16-18)}$ Por tanto, la situación de pandemia no parece haber derivado en un aumento de las complicaciones en las intervenciones de Cirugía Plástica analizadas.

Respecto a la aparición de complicaciones en las cirugías, analizamos la existencia en nuestra muestra de factores de riesgo clínicos previos y la aparición de complicaciones. Los resultados muestran que el $99.3 \%$ de los pacientes no presentó ninguna complicación sistémica, solo hubo un $0.1 \%$ de complicaciones respiratorias $(\mathrm{n}=2)$ y cardiovasculares $(\mathrm{n}=1)$ que fueron resueltas con éxito. Respecto a las complicaciones locales (Gráfico 2), el 96.7\% (679 casos) de los pacientes no experimentaron ninguna complicación y de las sucedidas $(3.4 \%, \mathrm{n}=24)$, la más frecuente fue la dehiscencia con un $1.6 \%(\mathrm{n}=12)$. Las complicaciones sistémicas no han sido significativas en nuestra muestra y las ocurridas no implicaron gravedad. Las complicaciones locales mostraron una incidencia mayor que las sistémicas, pero sin que detectáramos un incremento de las mismas que se relacione con el virus.

Se realizaron un total de 5 PCR posquirúrgicas, 3 de ellas correspondientes a los pacientes que habían presentado síntomas compatibles y 2 más en pacientes que presentaron indicios de clínica compatible poscirugía, resultando todas negativas. Este dato supone que se realizó PCR posoperatoria a un $0.71 \%$ de los pacientes. Buscando relacionar el tipo de anestesia con la incidencia de la COVID-19 analizamos los datos correspondientes a la PCR posoperatoria (Gráfico 3), ninguno de los tipos de anestesia se relacionó con una mayor tasa de infección

Gráfico 2. Complicaciones locales ocurridas durante las cirugías.

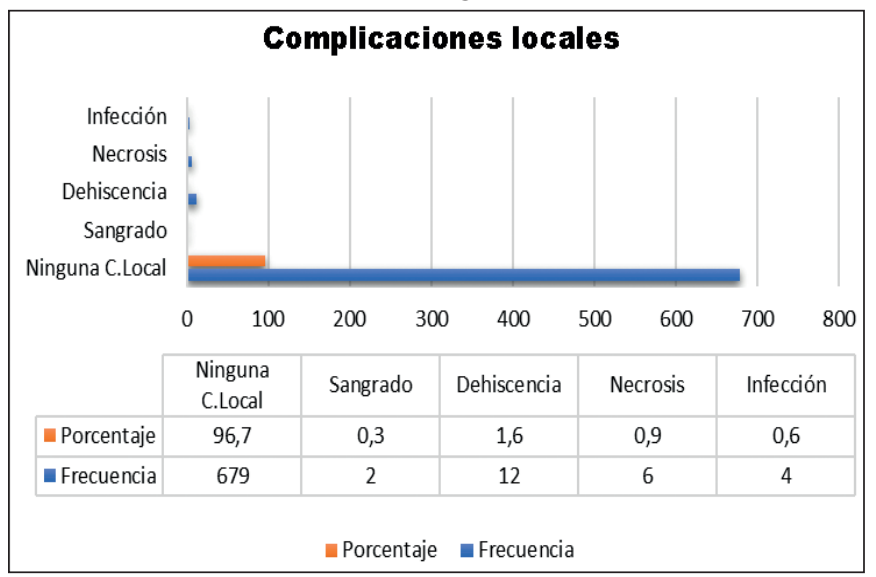


por SARS-CoV-2. Los pacientes que habían presentado clínica compatible volvieron a obtener un resultado negativo posoperatorio.

Otra de las variables de interés para el estudio fue el tiempo de cirugía empleado en cada intervención y cómo afectó esta variable al desenlace del caso, es decir, si un mayor tiempo quirúrgico puede relacionarse con una mayor incidencia de infección por SARS-CoV-2, ya que esta variable ha sido previamente estudiada con el objetivo de crear estrategias que mitiguen la aparición de complicaciones debidas a largos tiempos quirúrgicos. ${ }^{(19,20)}$ Recogimos los datos referentes a la duración de 451 cirugías (64.1\%); la de mayor extensión se completó en 12 horas y la de menor duración en 9 minutos (media de 77.97 minutos). Fueron 258 (57.2\%) las cirugías que se realizaron en un tiempo inferior a 60 minutos, 119 de

Gráfico 3. Resultados de las pruebas PCR posoperatorias realizadas.

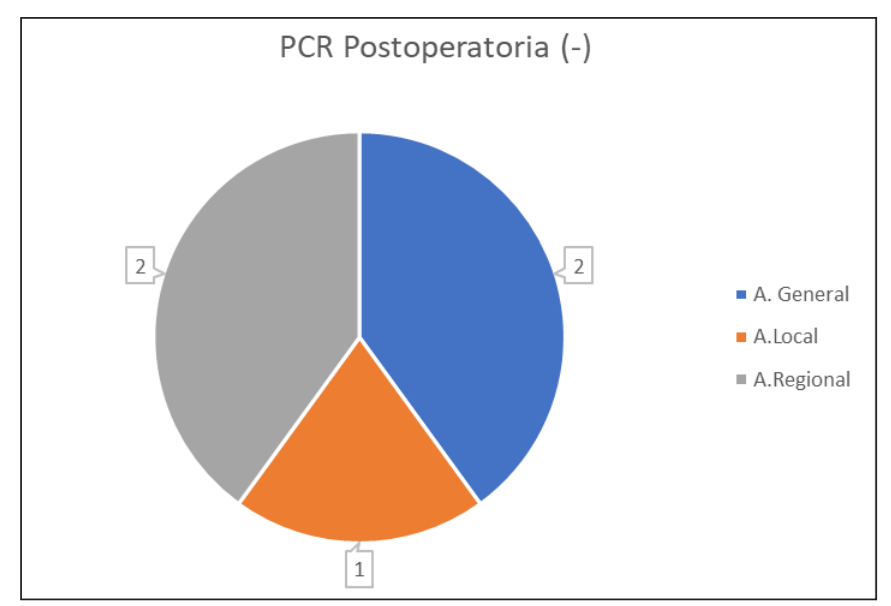

entre 60 y 120 minutos $(26.3 \%), 57$ de 120 a 240 minutos (12.6\%) y 17 de más de 240 minutos (3.7\%) (Gráfico 4). Los 24 casos de complicaciones locales en cirugías se distribuyeron de la siguiente manera: 13 casos se produjeron en cirugías de menos de 60 minutos, 2 en cirugías de entre 60 a 120 minutos y 9 en cirugías de entre 120 a 240 minutos.

Los pacientes de este estudio no precisaron prolongación del tiempo de cirugía, entendida como tal aquella no debida a la propia complejidad de la cirugía en sí. Este estudio no ha encontrado casos en los que se relacionara una infección por SARS-CoV-2 con una cirugía de larga duración.

\section{Discusión}

El emergente virus SARS-CoV-2 está siendo objeto de estudio de investigación no sólo en el ámbito quirúrgico como pretende este estudio, sino para el análisis del impacto en la formación y labor asistencial. ${ }^{(21)}$ Los profesionales coinciden en identificar las dificultades que ha supuesto esta situación, pero también la reconocen como oportunidad de aprendizaje y momento para la optimización de recursos. En nuestro estudio recogimos pacientes que habían sido intervenidos por Cirugía Plástica, con distintas características y potenciales riesgos. ${ }^{(22,23)}$ tomando las medidas establecidas por los protocolos vigentes en el momento, tal y como se ha hecho en otros centros de referencia como el St. Andrew's Hospital en el Reino Unido. ${ }^{(24)}$

Gráfico 4. Relación entre el tiempo de cirugía y las dos variables consideradas vinculantes a CoVID-19 achacables a realizar la intervención quirúrgica

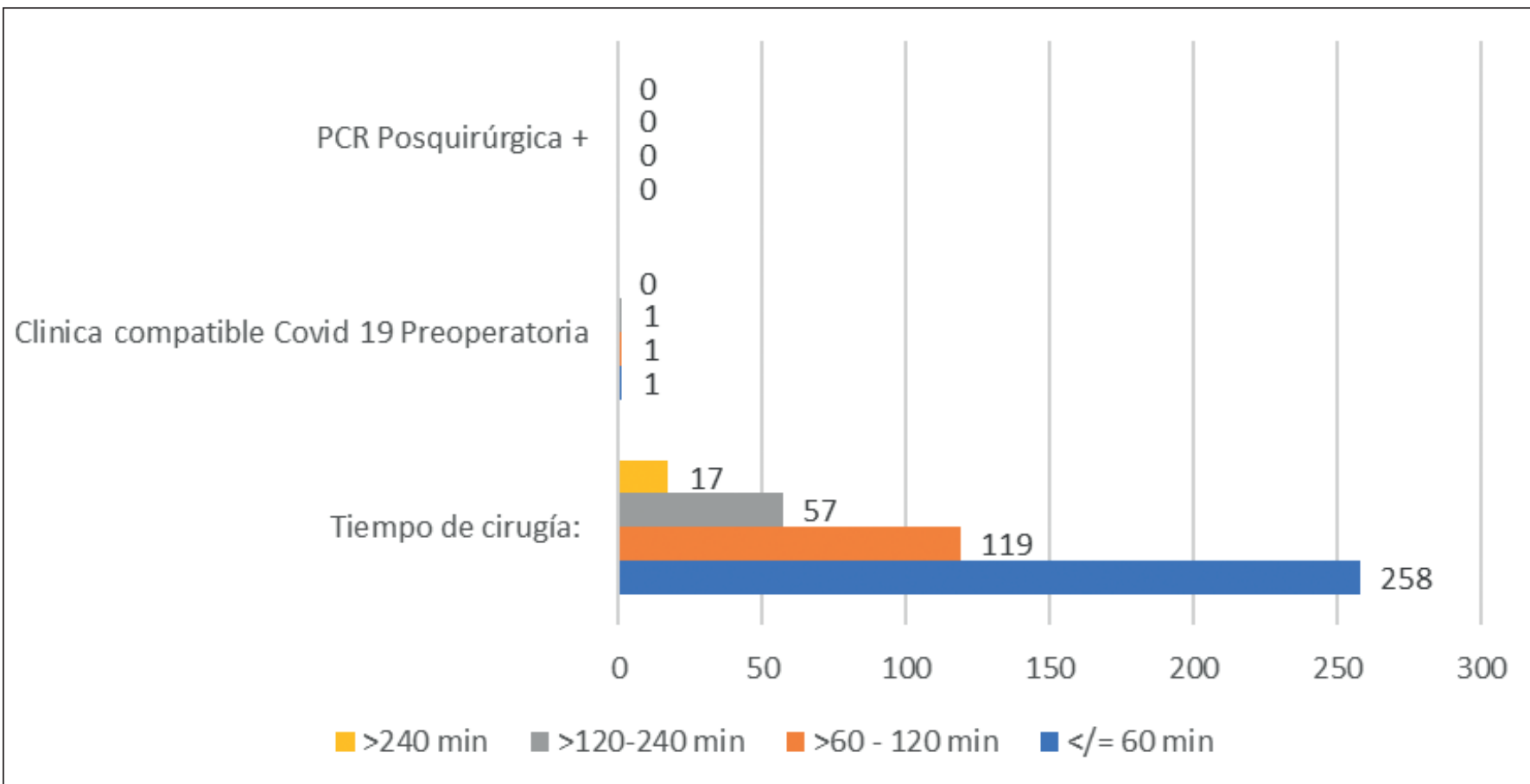


Es preciso mencionar que existe un sesgo en los tipos de cirugía realizados en este intervalo de tiempo, dado que, por normativas sanitarias, existió una reducción de las cirugías mayores. La situación de pandemia y los requerimientos de camas hospitalarias y asistencia a pacientes con COVID-19, motivó durante los meses de marzo a agosto una reducción significativa de las cirugías no urgentes en España, al igual que en otros países. Pudo existir también un sesgo en cuanto al tipo de cirugía, ya que se seleccionaron cirugías oncológicas y no demorables, por tanto, sería importante realizar estudios más amplios en los que no existiesen estas limitaciones quirúrgicas ni anestésicas. Pese a las circunstancias, fue posible realizar un estudio que reflejase el impacto de la COVID-19 en las intervenciones de Cirugía Plástica llevadas a cabo durante la primera fase de pandemia en nuestro ámbito geográfico regional.

El desconocimiento inicial de la enfermedad nos llevó a creer que las complicaciones y las tasas de mortalidad perioperatorias serían mucho mayores que las que existen en períodos de normalidad, ${ }^{(25)}$ sin embargo, los resultados de nuestro estudio nos inclinan a pensar que una correcta selección de los pacientes, la toma de precauciones que proponen los protocolos, y los chequeos diagnósticos preoperatorios, permiten realizar con seguridad las intervenciones programadas de Cirugía Plástica. Allan y col. ${ }^{(20)}$ ya comentaron la influencia de la prolongación del tiempo de cirugía y la duración de la estancia en el hospital en la aparición de complicaciones, encontrando una relación estadísticamente significativa entre la duración de la cirugía y las complicaciones médicas y quirúrgicas. Nuestro estudio no ha encontrado relación entre la complicación "infección por SARS-CoV-2" con el tiempo de realización de las cirugías y no observamos diferencias significativas entre las complicaciones ocurridas en este período frente a las acontecidas en períodos de normalidad.

Sin duda, la sistematización de la realización de prueba de PCR preoperatorias, test de antígenos o de anticuerpos según el paciente, y la toma de las mismas medidas al alta, aportaría a las unidades unos datos clínicos que servirían para optimizar los protocolos de actuación y para determinar con mayor exactitud el impacto de la pandemia en los pacientes quirúrgicos. Así, en el momento en el que iniciamos este estudio, consideramos que son necesarios más estudios en las disciplinas quirúrgicas que apoyen los resultados de que adoptar unas medidas de prevención apropiadas, conlleva una realización segura de las cirugías.

Nuestro estudio presenta los resultados correspondientes a un período de tiempo breve de recogida de datos (primeros meses de la pandemia) y circunscrito a una especialidad concreta y a una experiencia en un área geográfica del Sistema Nacional de Salud Español. Tiene como finalidad ir en la línea de las distintas investigaciones que se han realizado sobre la práctica segura de cirugías en el resto de Europa, así como las diversas propuestas de guías de actuación de las asociaciones científicas internacionales para retomar las intervenciones quirúrgicas $^{(26)}$ y la necesidad de establecer medidas para la seguridad que pasan por crear distintos protocolos: proveer al paciente de la información necesaria sobre cómo se procederá a su cita y programación de cirugía; establecer el riesgo de contagio según las características del paciente; considerar el riesgo según el tipo de intervención que se va a realizar, y llevar a cabo una preparación específica del personal sanitario que formará parte del equipo.(27)

Las recomendaciones para la cirugía en pacientes con enfermedades víricas altamente transmisibles a través de fluidos, recomiendan accesos mínimamente invasivos para minimizar el contagio a miembros del equipo quirúrgico. El equipo de protección individual (EPI) será necesario en cualquier procedimiento considerado como "contacto estrecho", lo que incluye las intervenciones quirúrgicas así como otros procedimientos de quirófano (intubación, anestesia regional, canalización de vías, etc.). Los equipos EPI disponibles proporcionan una protección eficaz frente a los riesgos que motivan su uso, sin suponer por sí mismos u ocasionar riesgos adicionales. Es fundamental que el equipo quirúrgico al completo haya realizado entrenamiento previo en su colocación y retirada supervisada y de forma previa al procedimiento real. Es asimismo muy importante la colaboración de todos los miembros del equipo quirúrgico entre sí. Debe haber personal entrenado disponible de reserva (de todos los estamentos) en caso de que se produzca algún imprevisto (que el personal no tolere el EPI, presente mareo por exceso de calor, etc.) Se recomienda también el uso de una lista de comprobación (check list) de todo el procedimiento que incluya explícitamente la situación COVID-19 del paciente. En relación a la anestesia, la AEC suscribe las recomendaciones que al respecto haga la Sociedad Española de Anestesiología, Reanimación y Terapéutica del Dolor (SEDAR); además será preciso limitar al máximo el número de profesionales que se encuentran en el interior del quirófano y sus movimientos para reducir el riesgo de contaminación.

\section{Conclusiones}

Este trabajo retrospectivo se planteó para comprobar y validar los datos recogidos sobre las intervenciones de Cirugía Plástica realizadas durante un período inicial de la pandemia de la COVID-19 en la Comu- 
nidad Autónoma de Andalucía, España. Los pacientes intervenidos en las unidades de Cirugía Plástica participantes en este estudio no han sufrido complicaciones que se vinculen a esta enfermedad y las complicaciones observadas no han variado significativamente respecto a períodos de normalidad, pudiendo resolverse con los procedimientos habituales y concluyendo todos los pacientes con un alta favorable.

No observamos que en las cirugías programadas haya habido contagios relacionados con la intervención. Los tiempos de cirugía no han supuesto mayor riesgo en lo referente al contagio por SARS-CoV-2 y el tipo de anestesia utilizado no se relaciona con la incidencia de complicaciones relacionadas con enfermedad ni contagio por el virus SARS-CoV-2.

Por tanto, situándonos en el período de tiempo en que se realizaron las intervenciones quirúrgicas de este estudio (marzo-abril 2020), los lugares donde se realizaron y en lo competente a Cirugía Plástica, fue seguro realizar las intervenciones siguiendo los protocolos establecidos, llegándose a la resolución favorable de los casos en su totalidad.

\section{Agradecimiento}

Un agradecimiento especial a los Dres. Joan Benítez, Purificación Gacto y Jesús Torres por su contribución a este trabajo

\section{Dirección del autor}

Dr. Alberto Redondo Camacho

Clínica RC

C/ Reyes Católicos 11

14001, Córdoba, España

Correo electrónico: redon-62@hotmail.com

\section{Bibliografía}

1. Wuhan seafood market pneumonia virus isolate $\mathrm{Wu}-$ han-Hu-1, complete genome. 23 de enero de 2020 [citado 7 de febrero de 2020]; Disponible en: http://www.ncbi.nlm.nih.gov/ nuccore/MN908947.3

2. Novel Coronavirus (2019-nCoV) situation reports [Internet]. [citado 15 de mayo de 2020]. Disponible en: https://www.who. int/emergencies/diseases/novel-coronavirus-2019/situation-reports

3. Paules CI, Marston HD, Fauci AS. Coronavirus Infections-More Than Just the Common Cold. JAMA. 2020;25;323(8):707708.

4. Coronavirus disease 2019 (COVID-19) pandemic: increased transmission in the EU/EEA and the UK -seventh update [Internet]. European Center for Disease Control and Prevention; 2020 mar. Disponible en: https://www.ecdc.europa.eu/sites/default/ files/documents/RRA-seventh-update-Outbreak-of-coronavirus-disease-COVID-19.pdf
5. Liu Y, Eggo RM, Kucharski AJ. Secondary attack rate and superspreading events for SARS-CoV-2. Lancet. 2020;14;395(10227):e47.

6. Lechien JR, Chiesa-Estomba CM, De Siati DR, et al. Olfactory and gustatory dysfunctions as a clinical presentation of mild-to-moderate forms of the coronavirus disease (COVID-19): a multicenter European study. European Archives of Otorhino-laryngology, 2020;277(8):2251-2261.

7. Yang CL, Qiu X, Zeng YK, et al. Coronavirus disease 2019: a clinical review. Eur Rev Med Pharmacol Sci 2020, 24(8):45854596.

8. Kannan S, Shaik Syed Ali P, Sheeza, AK. Hemalatha.COVID-19 (Novel Coronavirus 2019) - recent trends. Eur Rev Med Pharmacol Sci Year: 2020,24(4): 2006-2011

9. Li F, Li W, Farzan M, Harrison SC. Structure of SARS coronavirus spike receptor-binding domain complexed with receptor. Science. 2005; 309(5742): 1864-1868.

10. Rothan HA, Byrareddy SN. The epidemiology and pathogenesis of coronavirus disease (COVID-19) outbreak. J Autoimmun. 2020: 102433.

11. Giunta RE, Frank K, Moellhoff N, Braig D, Haas EM, et al. The COVID-19 Pandemia and its consequences for plastic surgery and hand surgery. Handchir Mikrochir Plast Chir. 2020 28. doi: 10.1055/a-1163-9009

12. Sociedad Española de Cirujanos. AEC. Disponible en: https:// www.aecirujanos.es/files/portalcontenidos//508/documentos/Pacientes_oncologicos_y_covid19_v2(1).pdf

13. Sociedad Española de Cirujanos. AEC. Disponible en: https://www.aecirujanos.es/files/portalcontenidos//508/documentos/Recomendaciones_AEC_en_CIRUGIA_DE_URGENCIASv2(1).pdf

14. Sociedad Española de Cirugía Plástica y Reparadora. SECPRE. Disponible en: https://www.secpre.org.; https://portalsecpre.org/.

15. Kaye K, Paprottka F, Escudero R, Casabona G, et al. Elective, Non-urgent Procedures and Aesthetic Surgery in the Wake of SARS-COVID-19: Considerations Regarding Safety, Feasibility and Impact on Clinical Management. Aesthetic Plast Surg. 2020;44(3):1014-1042.

16. Hernandez-Boussard T, McDonald KM, Rhoads KF, Curtin CM. Patient safety in plastic surgery: identifying areas for quality improvement efforts. Ann Plast Surg. 2015 May;74(5):597-602.

17. Stewart KJ, Stewart DA, Coghlan B, Harrison DH, Jones BM, Waterhouse N. Complications of 278 consecutive abdominoplasties. J Plast Reconstr Aesthet Surg. 2006;59(11):1152-1155.

18. Yazar S, Altinkaya A, Bengur FB, Karadag EC, Kara H, Uras C. Factors Associated with Complications in Immediate Breast Reconstruction in 1 Stage With Completely Submuscular Implants. Ann Plast Surg. 2019;83(3):264-270.

19. Brian J. et al. How Slow Is Too Slow? Correlation of Operative Time to Complications: An Analysis from the Tennessee Surgical Quality Collaborative. J. of the Am. College of Surgeons 2020, 220(4):550-558.

20. Allan J, Goltsman D, Moradi P, et al. The effect of operative time on complication profile and length of hospital stay in autologous and implant-based breast reconstruction patients: An analysis of the 2007-2012 ACS-NSQIP database. J. of Plast Reconst \& Aesth Surg,2020;73(7):1292-1298.

21. Dávalos DA, López Torres F. Impacto de la COVID-19 en la formación de residentes de Cirugía Plástica. Cir. plást. Iberolatinoam, 2020;46(2):121-124.

22. Aghagoli G, Gallo Marin B, Soliman LB, Sellke FW. Cardiac involvement in COVID-19 patients: Risk factors, predictors, and complications: A review. J Card Surg. 2020;35(6):1302-1305.

23. Khan S, Mian,A. Medical education: COVID-19 and surgery. The British J of Surg. 2020;107(8): e269.

24. Miranda BH, Ahmad F. et al. St Andrew's COVID-19 surgery safety (StACS) study: Elective plastic surgery, trauma \& burns. Journal of plastic, reconstructive \& aesthetic surgery. JPRAS, 2020;74(1): 211-222. 
25. Wexner SD, Cortés-Guiral D, Gilshtein H, Kent I, Reymond MA. COVID-19: impact on colorectal surgery. Colorectal Dis. 2020;22(6):635-640

26. Van Heijningen I, Frank K, Almeida F, Bösch U, et al. EASAPS/ESPRAS Considerations in getting back to work in Plastic Surgery with the COVID-19 Pandemic - A European point of view. Handchir Mikrochir Plast Chir. 2020;52(4):257-264.
27. Kapoor KM, Chatrath V, Boxley SG, Nurlin I, et al. COVID-19 Pandemic: Consensus guidelines for preferred practices in an aesthetic clinic. Dermatol Ther. 2020;33(4):13597. 